\title{
Media promotion and the forgotten heritage in the province of Guelmim
}

\author{
Malika Ait Nasser *
}

Laboratory Values, Society and Development (LVSD), and University Campus of Ait Melloul, Agadir, Morocco

\author{
Keywords \\ Media \\ Resources \\ Territory \\ Heritage \\ Development \\ Tourism \\ Guelmim
}

Received: 6 November 2019

Accepted: 15 January 2020

Published: 13 June 2020

\begin{abstract}
In this media/heritage resource articulation, this article assesses the effect of the media on the mobilization of local heritage resources. More precisely, we aim to identify mobilized resources in the forms of media compared to those not yet mediatized. The juxtaposition between media and territorial resources underlines the continuity of the intangible value of the territory in the pages of the newspaper, the television programs, the headings of the photographed sites, the video. They are also discussed based on major changes in information models such as social networks, portals, websites, etc. To answer the question regarding media and the promotion of the forgotten territorial heritage in the province of Guelmim, this study first established a census of the heritage resources mobilized in media and others ignored or marginalized. Both qualitative and quantitative methods were used to obtain data. On a sample of 20 municipalities over the 2014-2016 period in the province of Guelmim, our results indicate a significant number of rich but ignored heritage resources. Also, this study highlights the value of the diversity of the province's heritage and the opportunities that this wealth generates for the development of socio-economic activity such as tourism. This study has provided valuable insights for the policy makers and relevant officials.
\end{abstract}

(C) 2020 The Author(s). Published by TAF Publishing

\section{INTRODUCTION}

The territory acquires a specific importance by the presence of its particular and authentic heritage. With a wide scope in its definition, heritage is more than historic monuments since it generates a range of fairly varied goods between tangible and intangible, natural and human, historical heritage, natural potential, knowledge, etc. Heritage is therefore a common good, a common heritage transmitted between several generations. He is attached to an individual or a group belonging to a community, to a social structure (Bariscil, 2017; Francois, Hirczak, \& Senil, 2006; Hirczak et al., 2008).

Apart from its economic value (profitability, supply, revenue, etc.), heritage is a social relationship, an institution and an identity for the territory of its reception. It is, therefore, seen differently depending on the approach from which it is apprehended (Landel, Gagnol, \& Oiry-Varacca, 2014). In fact, exploiting the media/territories relationship is an example of media apprehension in the production of new spatial configurations and the socio-spatial imagination of a territory. This is how "to bring out the representations that make the territory meaningful in the eyes of the reader/viewer/internet user/inhabitant/citizen" (Noyer, I., \& Raoul, 2013).

In general, the variety of heritage resources does not necessarily introduce the attractiveness of the territory once its communication is neglected. So, how do the media contribute to the production of new territorial enhancements via heritage? To answer this question, the choice of the province and the analysis of the data collected as well as the interviews justify the opportunities generated from the mobilization in the media of local heritage.

In our field of study, the province of Guelmim, several types of heritage are worthy of mention. We developed them in the results section. According to the elements detailed and discussed in the following pages, we have identified the me-

\footnotetext{
* corresponding author: Malika Ait Nasser

†email: malikanacer@hotmail.com
} 
diatized heritage resources and others still ignored by the media before concluding with personal reflections on their enhancement via the media.

\section{LITERATURE REVIEW}

The territory feeds on its heritage variety in order to create activities that subsequently realize its identity and fulfillment for the mobilization of its heritage. As potentials, it would be able to support the construction of the expanse, thus becoming an active generator of economic activities. In fact, addressing the question of the heritage resource makes it possible to define the territory in its spatial dimension, its realization and its different users (economic, political, associative, etc.) by producing certain attractiveness for the valued and publicized territory.

The attractiveness of a territory according to Hazebroucq (1999) depends first of all on its basic infrastructure (transport, internet, airport, motorway, etc.) that are crucial amenities for the accessibility of a tourist area where a certain resource heritage is mobilized. However, Botti, Peypoch, and Solonandrasana (2008) reports that a locality does not need a spectacular attraction to become a tourist destination. It is from the moment that the tourist frequents and consumes a tourist space that it becomes a tourist good. With a little creativity and infrastructure, the locality acquires a certain attraction (Chang, Wu, Hsu, \& Yang, 2017). From another point of view, (Rochefoucauld, 2003) considers an attractive territory as soon as the population has a positive opinion of its culture since collective action can be one of the main axes of local development thanks to creativity and enhancement of local culture. Given these territorial resources, the intersection of sectors, cooperation between territorial services, the city's competitiveness in attracting investment and improving the pace of its development are based on a panoply of territorial components, including the media player is taken into account (Boujrouf, 2014; Campagne \& Pecqueur, 2014; Campaigne \& Pecqueur, 2014; Decleve \& Hibo, 2004; Hirczak et al., 2008; Herve \& Bernard, 2007).

According to Ouellet, Maille, Durand, Thibault, and Tableau (2011), efforts undertaken in the communication sector must not only concern themselves with integrating the rural into national and/or local development strategies. Giving a certain authenticity to the particularity of the destination is based on "the principle of information relay" (Decaudin, 2003; Luangsa-Art, 2016). This principle aims to improve the brand image of a tourist service or product targeting the dissemination of the tourist image of this area indirectly transmitted to final receivers (tourists, to, travel agency, etc.) via intermediaries (journalist, magazines,...).

In other words, the media, as an intermediary, in this principle of information relay, participates in the emergence of new formal figures of the territory (Noyer et al., 2013). In fact, exploiting the media/territory relationship co-constructs the territory in new images associated with the territory by the local actors of which the media is a part. So, we are witnessing new identities granted to the territory by highlighting a heritage deemed essential once publicized.

\section{METHODOLOGY}

As a new research field not exploited, the choice of the field of study is explained by the rich cultural heritage and the particularity of the province. administrative documents, the oficial website of the Guelmim-Oued Noun region, the tourist sites visits and direct interviews with officials and professionals in the tourism and culture sector help to compile informations for our research subject. As already mentioned in the map (Figure 1), we have chosen 9 communes out of 20 communes in total. To answer to the question The media and the promotion of the forgotten territorial heritage in the province of Guelmim, we first established a census of the heritage resources mobilized in media and and others ignored or marginalized. We used both qualitative and quantitative methods.

The first qualitative approach engaged institutional actors such as delegations of tourism and culture, local authorities, Regional Tourism Council (RTC), and tourism actors. We used direct interview with local actors (associations, tourism professionals, public actors, promoters of tourism projects, elected officials, etc.) through the development of an interview guide. The comments made and the results collected will be the raw material for the analysis of the questions in our interview guide. Our surveys are based on an interview guide conducted with 51 local actors, i.e. 9 elected officials, 6 public actors, 7 associative actors and 29 professionals (private actors). These actors intervene directly and indirectly at the regional, provincial and municipal levels in touristic activities and the protection and enhancement of heritage.

Otherwise, the qualitative method aims to compile a set of documents useful for understanding the process followed in carrying out heritage mobilization and enhancement projects, in the participatory aspect of the actors present in the territory of the province of Guelmim. It is a question of developing:

- A bibliography and analysis of available documents (programs, plans,reports, tourism projects, initiatives,...).

- An inventory of latent and patent tourist resources (Del- 
egation of Tourism, municipalities, associations, tourism professionals, etc.).

- The determination of tourism professionals and their mode of operation of tourism potential in terms of material and immaterial heritage (travel agencies, tour operators, managers of tourist units, guides, etc.).

- The compilation of the reports of the meetings held with this development perspective local through the mobilization of local heritage resources.

\section{RESULTS AND DISCUSSION}

The enhancement of heritage makes local heritage known and promotes the attractiveness of the territory. Through dissemination and promotion actions, this promotion makes the wealth of heritage accessible to a general public. Heritage is no longer a priority for the media. In fact, "heritage broadcasts are more about news (one- to two-minute footage from television news) than production" (Lamy, 1996). In this context, it is necessary to appeal to the media to pay more attention to heritage in order to bring generations together and to inform young people about their origins and stories. In the field of study, we found two categories of heritage resources: a limited part with good media coverage (the regional television channel, the press, radio) and a second important but not publicized.

\section{Mediated Tourist Resources \\ Local moussems as a religious connotation}

The most remarkable Moussem in the history of Guelmim is that of Sidi Mohamad Ben Amrou Allamté Allamtouni in the commune of Assrir. During the Moussem, a set of economic activities took place in the territory of Guelmim: materials from western Sudan, South Africa and north. The goods are transported in large convoys called "akbar alkafila" (the big caravan) made up of more than 1000 camels.

In their socio-economic value, the Moussems in the rural communes of the province are all linked to a certain saint from whom they take their name. The mobilization of economic activities around these festivities is a moments of meeting between the descendants of the saint, the chiefs of the tribes and economic exchanges.

\section{Historical value of the camel market}

It is a large camel market that attracts sellers and buyers from all over the southern regions of Morocco southen. Until the 1970s, it was a place of meetings, trade, barter, information sharing on the camel and admiration of the atmosphere that the presence of an immense number of camels in different sizes and shapes. The value has remained commercial, not historic.

\section{Oasis: Natural heritage mobilized in part in tourism}

Dated over 2000 years, each oasis is organized into several strata. First the palm trees which guarantee the freshness of the space and protect the other vegetarian layers from the harsh effects of the Saharan climate. Then settle small fruit trees (pomegranates, olive trees, ...) and finally vegetable crops, cereals, alfalfa or henna. This organization of the vegetation constitutes a microclimate which maintains temperature levels under the canopy of the palm trees. The oasis space offers a quality environment with environmental problems. In fact, because of the rural exodus, the scarcity of water resources, the oases until very recently are threatened with great acute degradations.

\section{Communication of know-how via museum articles}

It is a place of interpretation, a scenography of the culture of the circuits of commercial caravans, resources in the oasis and its surroundings. There are two main museums in the village of Tighmert in the rural community of Asrir. On the one hand, the Casbah museum is set up on the premises of an old residence over 300 years old of a large AHEL BLAL family who previously received caravans and had commercial relations in its old form of barter at the 1 'time. The Casbah is rented at a symbolic price. In return, it is arranged and preserved, for the memory, with this museum project reflecting in a way the relationship of the house with camel caravans by the presentation of the products of their experiences. The museum is the memory of the nomads of the Sahara without giving rise to the sale of the products collected. Items are collected and purchased from individuals in the Guelmim region to the borders with Mauritania.

On the other hand, the Caravanserai museum was set up in 2001 in an old house (over 300 years old) of a certain Qayed KAWRI. Double value also exists with the owner as is the case with the first museum: the protection of the old architecture and of historic value and the presentation of the items exhibited at the museum. The items were collected after their purchase from the local population from Guelmim to the Oued of Senegal. The museum offers two services: the display of antiques and the purchase and resale of local handicrafts.

\section{Diversity of Potential Non-Mediated Heritage Re- sources \\ Rahbat zraa (place of wheat)}

In the 1960s, it was the identical image of Jamaä Lafna square in Marrakech: it welcomed jewelry sellers, camel sellers, the shops of former Jewish traders, the Dalalat (wholesalers). It is also a space for local catering, singing. 


\section{Jewish culture in Guelmim}

The rural commune of Ifrane of the Anti-Atlas is the oldest cradle of the oldest Moroccan Jewish community (Perray, 2011). According to oral tradition, a Jewish community fled the tyranny of Nebuchadnezzar, king of Babylon and left Palestine in 587 BC crossing Egypt and then the edge of the Sahara until they arrived in the region of the valley of Oued Noun in the 4th century BC. Their presence in the region had a political, economic and religious role. The rural commune of Ifrane of the anti-Atlas is still a holy place for Moroccan Jews who came to honor the most important saint of the Jewish community Youssef Ben MIMOUN, paased away in the 5th century BC.

The Jewish community traced the economic fabric of it especially in the 19th century. In the old Medina of Guelmim, the Mellah (the residence of the Jewish community), shops, trade workshops and jewelry stores remain resistant to the oblivion of history through unrestored remains. The old Jewish quarter, where different cultures and religions converge on trade, was destroyed by the floods. The former district of the Jewish community in the Guelmim region is just an extension of the community from the rural (Ifrane AntiAtlas commune) to the urban (Guelmim urban commune). If the Jews initially settled in the rural commune of Ifrane, they participated, with the great merchant Birouk, in the 19th century, in the development of commercial activity throughout the Oued Noun region. The number of stores in Mellah (the old residence of moroccan jewish, some of which are still used for the same business activities to date, demonstrates the importance of business activities at the time.

\section{Old residences of historical figures}

The traditional houses of the great historical figures represent a specific resource: the particularity of its architecture and its history relating to the person influences. They are likely to be activated as soon as they are attractive to tourists (Campagne \& Pecqueur, 2014). The transformation of the house of Caïd Dahman is an experience which can be a good example of the revival of history by the opening of the house into a museum. A counter-scenario is the Kasbah of the Birouk family who expressed acceptance of any form of negotiation with the Culture Delegation and the Tourism Delegation for the restoration and "touristification" of a part of the large house dedicated to the exhibition of manuscripts, historical documents, articles, etc.

\section{Earth or stone construction: Specific traditional archi-} tecture

In addition to the tent as a habitat style, we also find earth or stone constructions reflecting a certain form of sedentary civilization (Perray, 2011). The ksour are simple piedà-terre for nomads. They adapt to the nature of the climate and the nature of the raw materials available on site. In this regard, we find two types of ksour those in stone and others in earth. Next to the ksour, there are the citadel granaries which exist in all sizes and in all types: glued to a cliff, perched on a rocky outcrop, of stone or earth, they are a place of shelter for goods or people. Stone or clay constructions represent an important skill which oscillates between the use of the material available on the construction site and the creativity of the local craftsman.

"A gadir" or "Ighrem" in the Amazeigh culture of southern Morocco means the granary of the community. It refers to a thick stone wall. "Tighremt" is a diminutive word meaning a small attic, less important and often family. This is the wall, the fortified collective housing. The differences in meanings constitute an intangible linguistic heritage richness worthy of being highlighted.

In the territory of Guelmim, there are two granaries which coexist for collective interests. The first is located on a high peak or on steep rocks. It is built to confront the dangers of war in case of need of refuge intended for a large community larger than the village (Naji, 2006). It is linked to the tribe as insurance against disasters (epidemic, war, flood, etc.). On the other hand, the second, accessible and practical, is intended for a small community, for the daily activities of the village (reserve of wheat, dates,...) for the needs of the households of the village.

In the study area, the Agadir N'Uguelly is a piton granary in the rural commune of Amtoudi. It is a quality site in its construction, in the know-how of its structural implementation. Its construction role targets mastery of the upstream and downstream parts of the Amtoudi Valley: a round citadel built with stone gangue and earth mortar. It is tangled with the rocks. Other granaries are built of raw earth.

Drainage galleries or "Khatarates": A hydraulic heritage As a tool for channeling groundwater from the mountains to the plain, the Khataras date back to at least the 11th century. It is a gallery several kilometers long, built in terracotta clay, dotted with wells allowing its maintenance. Khatarats are resources not yet exploited in the village of Taramgiste in the rural commune of Fask. 


\section{Hassani culture and ritual}

First, the consumption of Sahrawi tea is a real ritual where the protagonists are the jemâa, gathered to discuss a family, cultural, political or other subject around three glasses of tea described in local culture as follows: "the first glass is bitter like life, the second is sweet like love, the latter is soft like death ". A symbolic aspect for a common drink among all Moroccans and special among Sahrawis. The components of tea may contain other additives such as amber, aromatic plants. It has become a local product in the combination of tea leaves and other additives with specific doses.

Then, The rules of Hassani music dates back to the 18th century. She uses central instruments made up of "Tbal" as a kind of drum, a four-stringed lute, "Tidnit", and a harp reserved for women, called "A rdin". The electric guitar is introduced as a modern instrument. The region is a cultural mix between Berber and Hassani which also influences music. Still, Hassani music is falsely interpreted in evenings in other regions outside its cultural and musical context, this music is developed in fusion with singers from Mauritania and countries of South Africa, while it is marginalized nationally. In short, this repertoire is in great demand in international music if we take the example of singer Ali FARKATOURI who develops his musical repertoire according to the Hassani rhythm.

In addition, for centuries, Hassani was the language of commercial transactions and even in colonial times despite the presence of two foreign languages, French and Spanish. Traders from different parts of Africa have used Hassani for centuries as their business language for trade.

The linguistic and cultural richness of hassani goes through the quality of the Saharawi poetry. This poetic dialect praises love, beauty and nature. It is also used for seduction, praise or advice. It's an oral tradition that mixes fiction and reality. Besides the lyrics, there are also stories and riddles as oral culture. Finally, the habits and cultures relating to wedding, birth, hospitality and local gastronomy ceremonies are specific resources valued at the local level as an aspect of lifestyle and not as a component of local tourism product. Despite their value, they are still ignored and marginalized, on a national scale, in the conception of the diversity of the Moroccan tourist destination.

\section{Variety of sahrawi crafts}

First, the malhfa or Sahrawi Jabador and the jewels have more value inside the region than outside (the other regions of the Kingdom). The development of its geographic space goes through the Souk Dalalat (wholesale market) in the old Medina of the urban commune of Guelmim and in bazaars.
Blue in all its contrasts dominates in the Sahrawi male costume. White is very rare and reserved for important figures. The Deraa is a kind of wide gandoura split on the sides. For women, malhfa, with its Indian sari look, has several colors, several prices and qualities.

Then, the jewelry composed of anklets, bracelets, silver and stone rings and pearls constitute her adornment. The hairstyle is special with its braids and braids; it is rarely used, only for occasions like wedding ceremonies, festivals, etc. Finally, the Sahrawi tent reflects a whole tradition, a particular know-how in its weaving. Woven by women, it is made of several strips of canvas woven from goat and camel hair (Perray, 2011). The tent and the carpet are products in demand for the quality of their production: authentic products, made to order, personalized items. The marketing of these two handicrafts is linked to the mobilization of tourist activity. The construction of a large part of the Oued Chbika tent in its 2013 edition produced by the Kalifa cooperative for weaving tents in the town of Asrir gives an example of the link established between the promotion of local handicrafts and tourist activities.

\section{Manuscripts}

The presence of historical documentation in the hands of amateurs and in family libraries deprives the region of the mobilization of this resource of great historical and moral value. Collecting and welcoming them in an institutional setting such as the museum makes this resource specific in order to trace the broad outlines of the history of this territory.

\section{Sahat laabid (Place of slaves)}

Located in the rural commune of Asrir (Daouar Tighmert), the place of slaves is a place of music, suffering, dance, games, horse riding and culture. The slaves at the time came together to compose their music to express their suffering in song. "Ganga" was the song of the region's slaves at the time; it has now become a musical genre, developed in Gnawa. The name of this song is inspired, according to local oral tradition, from an instrument in the form of a tomb, "Tbal", from two facets used in Africa for hunting and orienting herds of animals and introduced to Morocco by slave traders. The passage from Ganga to Gnawa is ensured by the slave trade to the cities of Essaouira and Marrakech via the city of Guelmim.

\section{Rock engravings}

In the province of Guelmim, two rural communes welcome rock carvings on their territory: the rural commune of Fask and the rural commune of Amtedi- Guelmim. However, this 
resource has not really taken on importance in the tourism strategies implemented in the province. False guides know the locations of rock carvings well and introduce them to their hikes. The protection or "the security" of this resource has been repeatedly defied because of the ignorance of stone carriers. This caused the loss of a large number of engravings. Preservation is currently ensured by a few locals who are aware of the importance of this heritage.

\section{Historical wealth}

The creation of the city in the Oued Noun valley dates back to the Middle Ages. In the regions of the Sahara, the word Oued means not only the river but also the route, the dry place of a river. With the names Nùn, Nùl and Nuhul, the valley had been a place of sharing where the nomadic camel drivers gathered. Oued Nouq (river of camels) can also be the origin of this appellation. The name Noun was associated with the medieval city of southwest Morocco which belonged to the Lamta tribe. Noun Lamta had been the capital of the great Sahara, the chief town of the valley thanks to the commercial roles which it had played in the trans-Saharan commercial transactions between the South, the North and the East of Africa and Europe (Jamani, 2008; Perray, 2011). In the Muslim era, the new religion found its place easily through the presence of regular trade across the desert from the 8th century. The trans-Saharan axis was developed by the need for gold for the minting of currency, the slave trade and various goods; which had favored the mix between the Amazigh, Arab-Muslim and Jewish tribes.

The Almoravids (1059-1147) who succeeded the first dynasties in Morocco, were reinforced by the tribes of the Sahara. The town of Noun Lamta, known by trade, was a workshop for coin minting during the Almoravid dynasty. The objects found on the premises of the forgotten city of Noun Lamta are a great proof of link between the Saharan south and the other regions of the Kingdom.

Expeditions in the Sahara had continued with Sultan Mly Ismail in the 17th century and early 18th century, in order to control the caravan routes. Citadels and casbahs are built for this purpose. With the advent of Sultan Med Ben Abdallah (from 1757 to 1790), the city of Essaouira was the terminus for the traffic of caravanners crossing the Sahara, towards the end of the 18th century.

Before the period of protectorate of the French colonists, the region of Guelmim held so much the attention of the Alawite sovereigns since the region was since, and especially during the reign of Sidi Mohamed Ben Abdallah (18th century), the Saharan commercial capital and the commercial link between Morocco and Africa.

The beginning of the colonial era favored privileges for foreign powers by devaluing the power of the sultan. During the French protectorate, from 1912, Spain took advantage of the situation to strengthen its presence in the territory known as Spanish West Africa. Their installation had provoked the indignation of the tribes, which led them to seek the intervention of Sultan Hassan I. in 1301 and 1305 of the Hegira, the province of Guelmim was honored by the visit of Sultan Hassan I who, on this occasion, gave Dahirs to the chiefs of the tribes of the Sahara in their zone of influence by making them responsible for the protection, surveillance of the Saharan territory from its coast of Foum Assaka (Ta rgaWasay commune in the province of Guelmim) to Oued Dahab (the province of Dakhla) against the French and Spanish occupation. He granted Sheikh Maa El Aynain the title of special representative responsible for carrying out the Kingdom's policy on Saharan territory by giving him support in arms and money. This gave rise to the holy wars against Spanish and French foreign colonization. After independence in 1956 and the recovery of the southern provinces in 1975, the big challenge remains its development. In general, the Saharan Moroccan territory was influenced by the comings and goings of the dynasties given its geographical importance for the national territorial unit and for the trade, linking the north to the south of Africa and Africa to the Europe.

\section{CONCLUSION}

The media represent a new conception of constantly changing territories. The rise of new media participates in or targets the visibility and enhancement of territories. The enhancement of local heritage, as in the case of the province of Guelmim, will give birth to a panoply of lines of intervention to disseminate the importance of local heritage. We have summarized our thoughts as follows: 


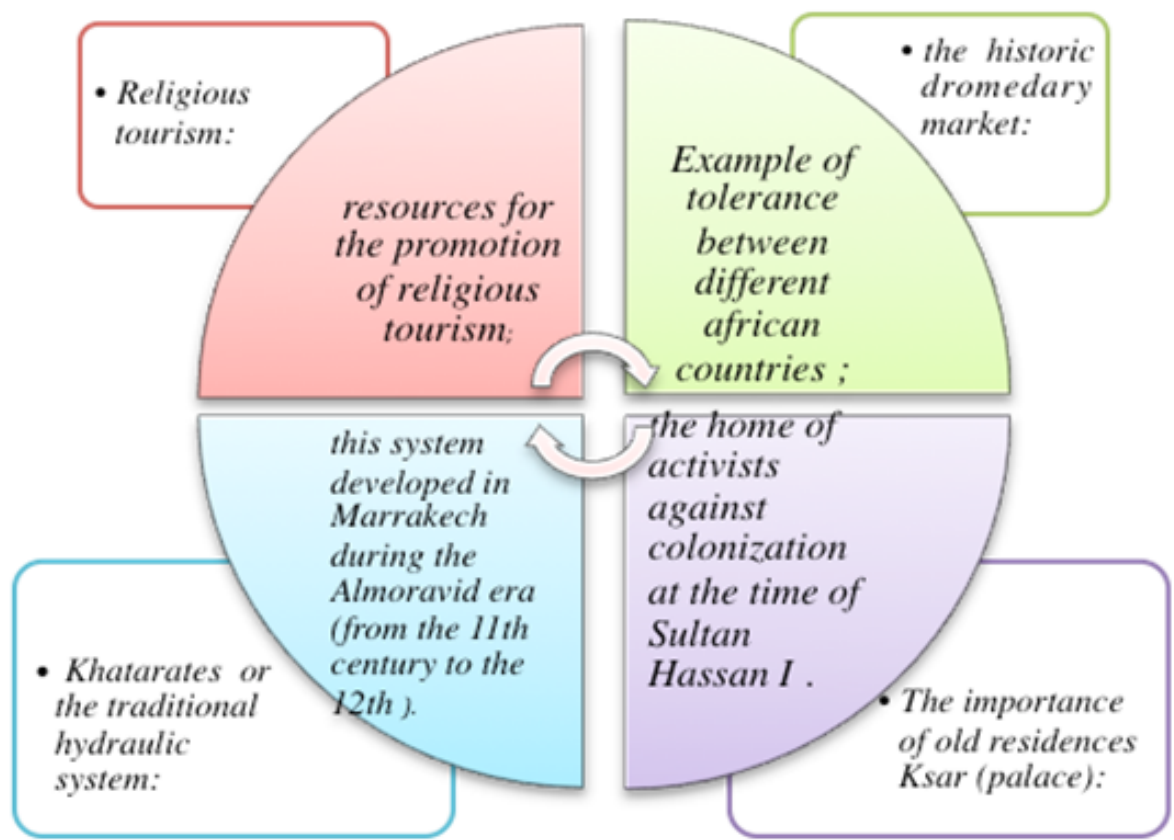

FIGURE 1. The essential heritage resources to be publicized for the region of guelmim

- Religious tourism around the Moussems is an opportunity for national tourism. The presence of the Jewish saint Youssef Ben MIMOUN is associated with this dynamic of the Moussems as resources for the promotion of religious tourism in the province.

- The resuscitation of the human, cultural and historical value of the dromedary market gives the region the image of "free land between different nationalities" as an example of tolerance between big merchants (Moroccans, Malians, Senegalese, Nigeriens, and d 'others) of camels and other items.

- The oasis ecosystem is an enhancement of an entire culture at the heart of the history of great Moroccan civilizations as a place of exchange, of solidarity within a hostile climate. Such a space constitutes a juxtaposition of tangible and intangible heritage for the conception of oasis tourism appropriate to the nature of this ecosystem.

- The importance of old residences is real proof not exploited to develop the tourist and historical value of the city. Ksar (palace) of Caïd Dahman, in the urban commune of Guelmim, is the home of an activist against colonization at the time of Sultan Hassan I whose value is ignored.

- The presence of the Khatarates links the town with the hydraulic system also developed in regions like that of Marrakech during the Almoravid era. The back and forth of know-how between the north and the south of the country still weaves the historical links between the south of Morocco and the other cities of the Kingdom.

- The museum, cultural meetings and themed tourist cir- cuits are ways of developing the cultural and historical aspect of the region in its position on a national and continental scale. Such a resource, once mobilized, strengthens the province's tourism products and highlights the importance of the region's history.

Many media explore different social networks, not only to disseminate information, but also to develop real projects to promote and mediate their collections or their content. For example, storytelling develops a narrative universe on several media platforms (Television, Internet, mobile, radio, publishing, etc.); each, according to its technological specificity, offers a complementary look at the universe and history in order to create a unique cultural entertainment experience of the Moroccan Sahara. Despite the mediocre attempts of the regional television channel "Layoune" in storytelling, a remarkable number of heritage resources not yet publicized. In this case, going digital has become a cultural, political or economic priority. In this ever-changing landscape, it is now a question for field medias of being visible and readable by everyone and on all networks by mastering new procedures and technologies.

In general, the media, as the main actor for the dissemination of information on the particularity of local heritage. As pointed out in the words of local actors, the territories of the provinces of southern Morocco are in the construction phase and not in evaluation, in which the media have their say in the major local development projects, including the enhancement of heritage. 


\section{REFERENCES}

Bariscil, A. (2017). Some aspects of the competitiveness of Turkish regions and their tourism industry the example of Ardahan. Journal of Advances in Humanities and Social Sciences, 3(6), 311-323. doi:https://doi.org/10.20474/jahss $-3.6 .3$

Botti, L., Peypoch, N., \& Solonandrasana, N. (2008). Tourism engineering, concepts, methods, applications. Brussels, Belgium: Boeck Press.

Boujrouf, S. (2014). Heritage and development resources of tourist territories in the high Atlas and the Southern regions of Morocco. Journal of Alpine Research, 102(1), 1-6. doi:https://doi.org/10.4000/rga.2259

Campagne, P., \& Pecqueur, B. (2014). Territorial development: An emerging response to globalization. Paris, France: ECLM. Campaigne, P., \& Pecqueur, B. (2014). Territorial development. New York, NY: New Imprimerie Laballery.

Chang, T. C., Wu, S. F., Hsu, S. C., \& Yang, C. C. (2017). A study of the tourism industry in East Taiwan. Journal of Advanced Research in Social Sciences and Humanities, 2(1), 61-66. doi:https://doi.org/10.26500/jarssh-02-2017-0108.

Decaudin, J. M. (2003). Marketing communication, concepts, techniques, strategy. Paris, France: Economica.

Decleve, B., \& Hibo, D. (2004). D'e territorial development and cultural mutations. Ottignies-Louvain-la-Neuve, Belgium: Leuven University Press.

Francois, H., Hirczak, M., \& Senil, N. (2006). Territory and heritage: The co-construction of a dynamic and its resources. Revue dEconomie Regionale Urbaine, 5(5), 683-700.

Hazebroucq, J. M. (1999). Management of tourism and leisure projects. London, UK: Gaetan Morin Press.

Herve, G., \& Bernard, P. (2007). The territorial resource. Paris, France: Economica.

Hirczak, M., Moalla, M., Mollard, A., Pecqueur, B., Rambonilaza, M., \& Vollet, D. (2008). From the basket of goods to a more general model of territorialized complex goods: Concepts, analysis grid and questions. Canadian Journal of Regional Science, 31(2), 366-400. doi:https://doi.org/10.4000/economierurale.366

Jamani, A. (2008). The oasis of asrir, elements of social history of the wadi noun. Rabat, Morocco: Crossroads Publisher.

Lamy, Y. (1996). L'alchimie du patrimoine: Discours et politiques. London, UK: MSHA.

Landel, P. A., Gagnol, L., \& Oiry-Varacca, M. (2014). Territorial resources and tourist destinations: Couples with a bright future? The cases of saffron production at Taliouine (Morocco) and onion production in the Air (Niger). Journal of Alpine Research, 5(8), 102-110.

Luangsa-Art, N. (2016). Guideline in developing a tourism route: A case study of Tambon Bang Nok Khwaek, Samutsongkharm province. International Journal of Humanities, Arts and Social Sciences, 2(3), 101-104. doi:https://doi.org/ 10.20469/ijhss.2.20003-3

Naji, N. (2006). Collective granaries of the atlas, heritage of southern Morocco. Casablanca, Morocco: Edisud and La Croisee des Chemins.

Noyer, J., I., P., \& Raoul, B. (2013). Media and territories: Public space between communication and territorial imagination. California, CA: Presses University Press.

Ouellet, J., Maille, M., Durand, D., Thibault, C., \& Tableau, I. (2011). Continuing education for the nursing profession in quebecprofessional standard. California, CA: Sage Publications.

Perray, C. (2011). Morocco Saharan of today. Paris, France: Du Jaguar.

Rochefoucauld, B. D. L. (2003). Tourism economy. Paris, France: Breal Publication. 


\section{Appendix}

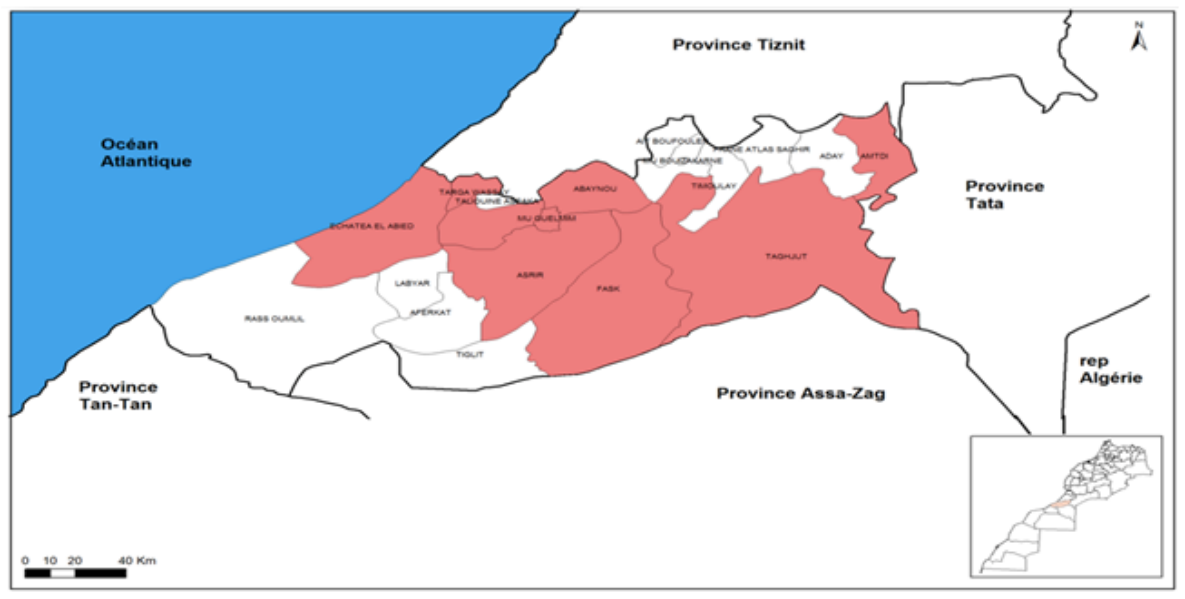

FIGURE 2. Map of field studies
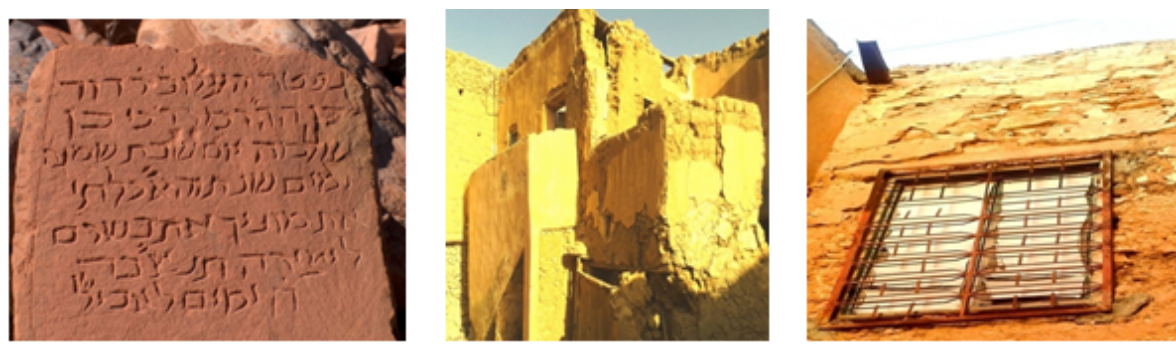

FIGURE 3. Annex 2 : Photos of local heritage resources Building of the jewish community in rural zone «Ifran » and the medina of Guelmim
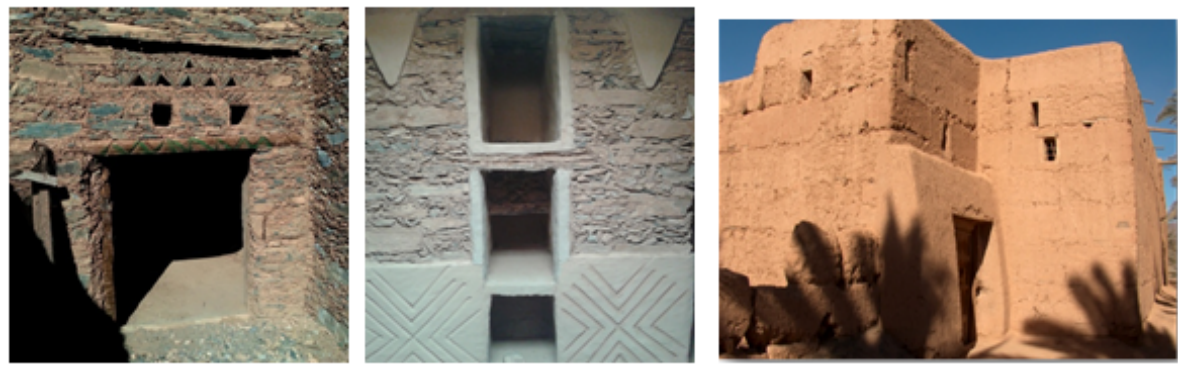

FIGURE 4. Traditional house in the rural communities of Guelmim
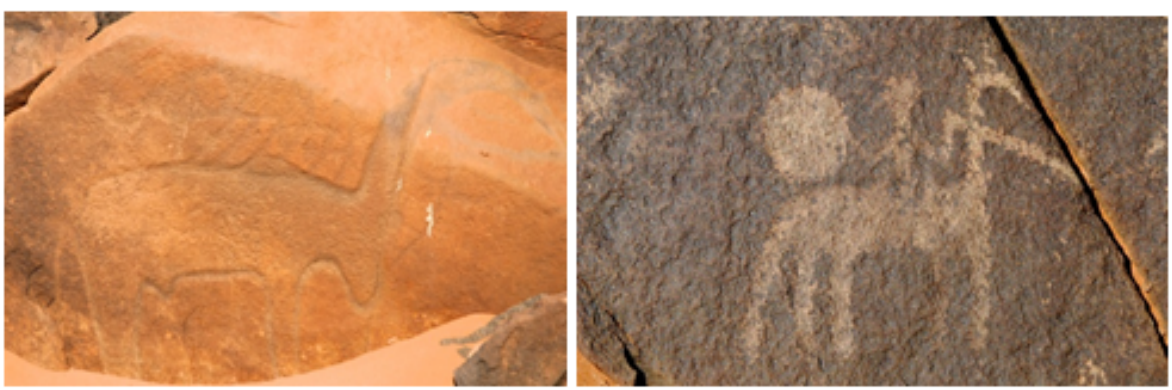

FIGURE 5. Rock engravings in the town of Fask-Guelmim 


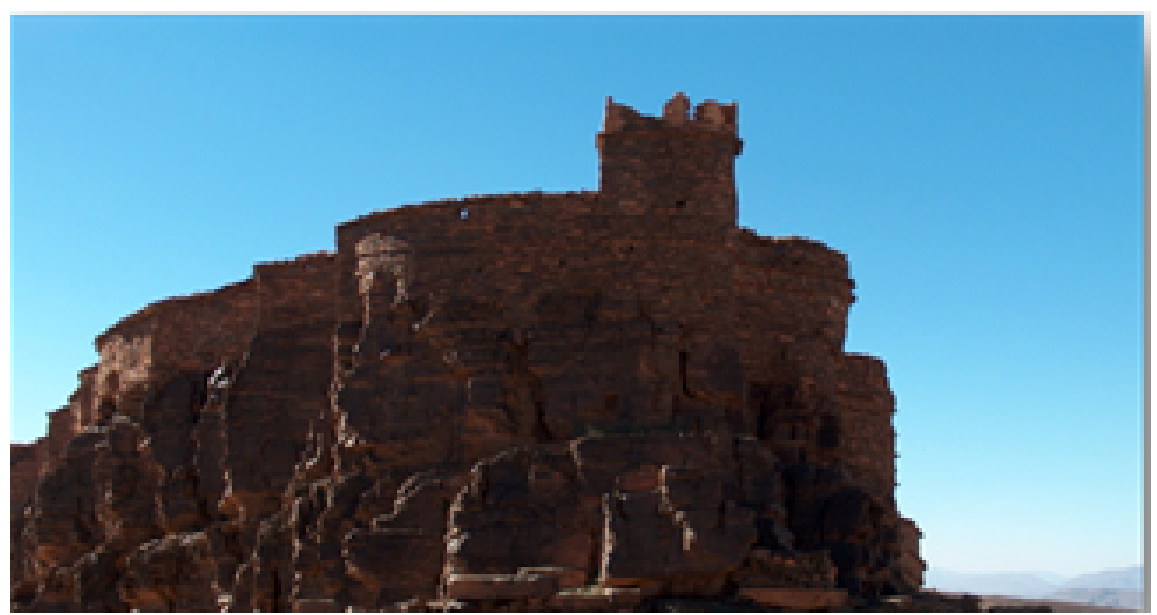

FIGURE 6. Casbah of agadir in amtoudi-Guelmim

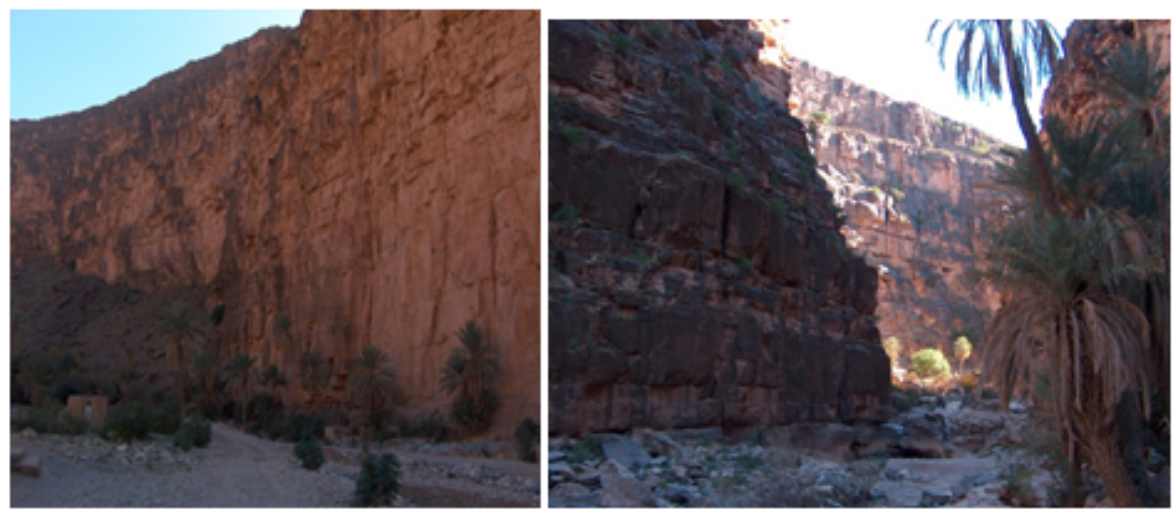

FIGURE 7. Id Aîssa Gorges in the rural commune of Amtedi-Guelmim 